\title{
Mycoviruses infecting the endophytic and entomopathogenic fungus Tolypocladium cylindrosporum
}

Noemí Herrero and Iñigo Zabalgogeazcoa

Instituto de Recursos Naturales y Agrobiología de Salamanca, Consejo Superior de Investigaciones Científicas (IRNASA-CSIC). Cordel de Merinas 40-52, 37008 Salamanca, Spain.

\begin{abstract}
Herrero N, Zabalgogeazcoa I. 2011. Mycoviruses infecting the entomopathogenic fungus Tolypocladium cylindrosporum. Virus Research 160: 409-413

A mixed virus infection in a strain of the endophytic and entomopathogenic fungus Tolypocladium cylindrosporum was deduced from a study of the transmission to conidia of several double-stranded RNA (dsRNA) elements. The transmission rates of each dsRNA were different, and monosporic isolates harbouring different combinations of the original set of six dsRNAs were obtained. A 5196 bp dsRNA element was sequenced and represents the genome of Tolypocladium cylindrosporum virus 1 (TcV1), a new member of the genus Victorivirus in the Totiviridae family. This virus was transmitted to $81.4 \%$ of the conidia; in contrast, four dsRNAs of 3.1-3.7 kbp were transmitted only to $4.7 \%$ of the monosporic isolates obtained from the infected parental strain. These four dsRNAs did not show segregation during transmission, one of them was sequenced and encoded an RdRp, suggesting that the four molecules might represent the whole genome of a multipartite chrysovirus. A third possible virus with a genome of approximately $4.2 \mathrm{kbp}$ was transmitted to $79.1 \%$ of the monosporic isolates produced by the infected strain. Ribavirin was used to cure T. cylindrosporum from viruses, and TcV1 was sensitive to this drug. All monosporic cultures derived from the infected strain treated with 80 and $100 \mu \mathrm{M}$ concentrations of the drug were free of TcV1.
\end{abstract}

Keywords: mycovirus, dsRNA, ribavirin, transmission, victorivirus

The ascomycete Tolypocladium cylindrosporum (Fam. Ophiocordycipitaceae) was first reported as a soil-borne species, and later as a pathogen of several species of insects, including mosquito genera like Anopheles and Aedes (Gams, 1971; Lam et al., 1988). The fungus is also pathogenic to crustaceans and arachnids like the ticks Ornithodoros erraticus and O. moubata (Herrero et al., 2011). In addition, this fungus has been isolated as an endophyte from leaves of some grasses (Sánchez Márquez et al., 2010). Other entomopathogenic fungi like Beauveria bassiana, Lecanicillium lecanii, or Metarhizium anisopliae have also been reported as endophytes 
and soil inhabitants, and have been tested as biological control agents for invertebrate plant pests (Vega et al., 2008).

The presence of dsRNA molecules of viral origin has been reported in endophytic strains of T. cylindrosporum, and other species of entomopathogenic fungi such as B. bassiana, M. anisopliae and Paecilomyces spp. (Herrero et al., 2009; Inglis and Valadares-Inglis, 1997; Melzer and Bidochka, 1998). However, in none of these cases were these viruses classified.

Mycoviral infections can be very persistent and difficult to eliminate from their hosts (Martins et al., 1999; Romo et al., 2007). Different attempts to cure fungi from viruses have been reported, e.g., cycloheximide treatments, single conidium subculture, hyphal tip transfer, incubation at low or high temperatures (Carroll and Wickner, 1995; Romo et al., 2007; Souza-Azevedo et al., 2000), but they were not always successful. These difficulties to cure fungi from viral infections, plus the lack of simple methods for the artificial inoculation of mycoviruses, have greatly hampered progress in exploring mycovirus-host interactions (Ghabrial and Suzuki, 2009).

The purpose of the present work was to identify some of the mycoviruses associated to $T$. cylindroporum, to study their transmission to asexual spores, and to test if they can be cured using the antiviral ribavirin, in order to obtain virus free isolates that could be used in further studies concerning to the effects of mycoviruses in this interesting fungal species.

Strain 11 of T. cylindrosporum, isolated as an endophyte from asymptomatic leaves of the grass Holcus lanatus in natural grasslands of Salamanca (Spain) (Sánchez Márquez et al., 2010), harbours six dsRNA elements of approximately 5.1, 4.2, 3.7, 3.4, 3.2, and $3.1 \mathrm{kbp}$, and it is pathogenic to the ticks Ornitodoros erraticus and O. moubata (Herrero et al., 2009). These dsRNA elements will be referred according to their size, dsRNA1 being the largest, and dsRNA6 the smallest (Fig. 1). To determine if all these dsRNA elements were transmitted to conidia, monosporic isolates obtained from strain 11 were analyzed. Strain 11 was grown in potato dextrose broth (PDB) under shaking $(110 \mathrm{rpm})$ for 12 days at $24{ }^{\circ} \mathrm{C}$. After this period the culture was filtered trough sterile gauze and centrifuged for $5 \mathrm{~min}$ at $800 \mathrm{x}$ g. The pellet was resuspended in water and different dilutions of the suspension were added to water agar plates. To obtain each monosporic isolate, single germinated conidia were collected under the microscope and plated in potato dextrose agar (PDA) plates. In parallel, strain 11 was cultured as above in two different curing media consisting of PDB containing 80 or $100 \mu \mathrm{M}$ of ribavirin. Ribavirin is a nucleoside analog that induces mutations in RNA viral genomes, and its range of biologically active concentrations is 10 to $100 \mu \mathrm{M}$ (Parker, 2005). This drug has been used in therapy against human RNA viruses such as hepatitis virus $\mathrm{C}$ or herpes virus, and against plant potyviruses (Mahmoud et al., 2009; Parker, 2005). However, it was not effective against a fungal virus infecting Chalara elegans (Park et al., 
2006). Monosporic isolates from each ribavirin treatment were obtained as explained before. For mycovirus detection all the monosporic isolates were cultured for three weeks over cellophane disks layered on top of PDA plates, after this period the mycelium was harvested, and dsRNA was extracted by CF-11 cellulose chromatography (Morris and Dodds, 1979). Isolates apparently cured of infection by all mycoviruses were analyzed two additional times.

To check which dsRNA elements were encapsidated in protein particles, twenty grams of mycelium were used to obtain partially purified virus preparations, as well as sucrose gradient purified preparations (Jiang and Ghabrial, 2004). Partially purified virus preparations from strain 11 were treated to disrupt virions by incubation for $20 \mathrm{~min}$ at $60^{\circ} \mathrm{C}$ in the presence of $0.1 \%$ SDS, followed by extraction with 1 volume of phenol:chlorophorm (1:1). The aqueous phase was ethanol precipitated, and the presence of dsRNA was checked by electrophoresis. The six dsRNAs infecting T. cylindrosporum were recovered from the aqueous phase obtained after the disruption treatment. This result suggested that all six dsRNA elements are encapsidated in protein particles, naked dsRNA would not sediment at the high speed used for particle purification (Zabalgogeazcoa et al., 1998).

Different dsRNA elements showed different rates of transmission to mitotic spores. Among the 43 monosporic isolates obtained from strain 11, dsRNA1 was present in $81.4 \%$ of the isolates, and dsRNA2 was transmitted to $79.1 \%$ of the monosporic isolates, alone or together with dsRNA1. dsRNAs 3, 4, 5, and 6 showed the same rate of transmission, they were present only in $4.7 \%$ of the isolates, and always accompanied by dsRNA1 and dsRNA2. These results suggest that the six dsRNA elements are the product of a multiple virus infection. Isolates infected only by dsRNA1 or by dsRNA2 were obtained. However, dsRNAs 3, 4, 5, and 6 did not segregate in conidial progeny. Therefore, dsRNA1 could be the genome of a virus, dsRNA2 the genome of another virus, and the four remaining dsRNAs could represent the multipartite genome of a third virus. In all reported cases of naturally ocurring mixed virus infections in fungi (i.e. Fusarium graminearum, Gremmeniella abietina, Epichloë festucae, Heterobasidion annosum) all the viruses infecting a strain were transmitted together to the conidial progeny (Chu et al., 2004; Ihrmark et al., 2002; Romo et al., 2007; Tuomivirta and Hantula, 2005). In contrast, in T. cylindrosporum different rates of transmission occurred for each virus, with values ranging from $4.7 \%$ to $81.4 \%$, depending on the virus. To our knowledge this is the first report of differential transmission rates among viruses in naturally occurring mixed infections.

In the absence of ribavirin $7.0 \%$ of the isolates were free of dsRNA, with $80 \mu \mathrm{M}$ ribavirin (47 monosporic isolates analyzed) $44.7 \%$ of the monosporic isolates were free of all six dsRNAs, and the rest only harboured dsRNA2. With the $100 \mu \mathrm{M}$ ribavirin treatment (48 isolates analyzed) 
$20.8 \%$ of the isolates were completely cured, and the remainder harboured only dsRNA2. The effectiveness of ribavirin seemed to be different for each dsRNA element. All the monosporic isolates were free of dsRNA1 at both concentrations, in the absence of ribavirin; the rate of transmission of dsRNA1 to conidia was $81 \%$. In contrast, dsRNA2 was not as sensitive, and its percentage of transmission to conidiospores ranged from $55.5 \%$ to $79.2 \%$ for isolates treated with 80 and $100 \mu \mathrm{M}$ ribavirin, respectively. The natural transmission of dsRNA2 to asexual spores was 79.1\%, almost the same observed with $100 \mu \mathrm{M}$ ribavirin. The natural transmission of dsRNAs 3, 4, 5 and 6 to conidia was very low (4.7\%); and it is difficult to evaluate the effect of the drug in the elimination of these dsRNAs.

dsRNA purified from strain 11 was used as a template for the synthesis of a cDNA library. About $2 \mu \mathrm{g}$ of dsRNA dissolved in water were denatured at $95^{\circ} \mathrm{C}$ for $10 \mathrm{~min}$ in the presence of 10 $\mu \mathrm{g}$ of $\quad \mathrm{a}$ degenerate $\quad$ primer $\quad$ (Totioligo: 5' $\left.\operatorname{TTGAA}(\mathrm{A} / \mathrm{G}) \mathrm{TC}(\mathrm{A} / \mathrm{G}) \mathrm{TC}(\mathrm{A} / \mathrm{G}) \mathrm{TA}(\mathrm{A} / \mathrm{G}) \mathrm{TC}(\mathrm{G} / \mathrm{C}) \mathrm{A}(\mathrm{A} / \mathrm{G}) \mathrm{CA}-3^{\prime}\right)$. The design of this primer was based on the alignment of motif IV of the RNA-dependent RNA polymerase (RdRp) sequences of seven members of the Totiviridae family (Supplemental material Table 1). The heat-denatured mixture was cooled and cDNA was synthesized using the Universal RiboClone cDNA Synthesis System (Promega) and cloned in pGEM-T vector (Promega). Escherichia coli strain JM109 (Promega) was transformed and screened for recombinant plasmids. Thirty five different cDNA clones were sequenced and used to assemble three contigs. Northern blot hybridization of dsRNA extracts from strain 11 with probes complementary to each contig, showed that two contigs were complementary to dsRNA1, and the other one to dsRNA3 (Supplemental material Fig 1.). The gap between the two contigs complementary to dsRNA1 was completed by reverse transcription and PCR using primers complementary to sequences flanking the gap was developed, repeating this experiment three times. Four identical clones of the 5' end and five of the 3' end of dsRNA1 were sequenced from two independent RLM-RACE experiments (Coutts and Livieratos, 2003). To obtain a complete sequence of dsRNA3, four identical cDNA clones of the 5' end and three of the 3' end from two independent RLM-RACE experiments of each terminus were sequenced.

The complete sequence of dsRNA1 had $5196 \mathrm{bp}$, and contained two open reading frames (ORFs) (Fig. 2A). ORF1 consists of $2277 \mathrm{bp}$ and encodes a hypothetical 758 amino acid protein (79.9 kDa); ORF2 is $2523 \mathrm{bp}$ long and encodes an 840 amino acid protein (91.2 kDa). Both ORFs are in the same reading frame, the UAA stop codon from ORF1 is directly followed by the AUG start codon of ORF2. No other possible ORFs longer than 350 nucleotides were found in any strand. The complete genome has a GC content of 61\%. The 5' untranslated region (UTR) has $326 \mathrm{bp}$ and a GAAAT sequence in its terminus, similar to the GAAAA motif present in the genomes of Ustilago 
maydis Virus (UmV) and the Saccharomyces cerevisiae viruses ScV-LA and ScV-L BC (Fujimura and Wickner, 1988; Kang et al., 2001). The 3' UTR has a length of $70 \mathrm{bp}$. The amino acid sequence deduced from ORF1 of dsRNA1 showed highest similarity to those of the capsid proteins (CP) of viruses of the family Totiviridae, particularly to that of Botryotinia fuckeliana virus 1 (BfV1; 61.5\%). The C-terminus of this putative CP has an Ala/Gly/Pro-rich region, which occurs in mycoviruses of the Victorivirus genus (Ghabrial and Nibert, 2008). A sucrose gradient purified virus preparation of strain 11-1L, obtained from the transmission experiments and harbouring only dsRNA1 was made according to Jiang and Ghabrial (2004). Isometric virus like particles of approximately $50 \mathrm{~nm}$ of diameter were observed transmission electron microscopy (Fig. 2C). Part of this virus preparation was analyzed by SDS-PAGE (Laemmli, 1970), and Coomassie blue staining of the gel showed a major polypeptide with an apparent molecular mass of $79.70 \mathrm{kDa}$ (Fig. 2D). This size is very similar to that expected from the hypothetical protein of 758 amino acids encoded by ORF1 $(79.87 \mathrm{kDa})$. This supports that ORF1 encodes the CP of the virus whose genome is dsRNA1. The deduced amino acid sequence of ORF2 from dsRNA1 resembled those of RdRps of the Totiviridae, particularly that of BfV1 (49\% identity). The eight conserved motifs of the sequences of RdRps of dsRNA viruses of simple eukaryotes (Bruenn, 1993) were present in this amino acid sequence. The size of dsRNA1 and its genes indicated that this molecule could constitute the genome of a virus belonging to the Totiviridae family. We nominated this new virus Tolypocladium cylindrosporum virus 1 ( TcV1), and its complete genome sequence has been deposited in the EMBL nucleotide sequence database with accession number FR750562.

dsRNA3 had a length of 3486 bp, and contained a 3399 bp ORF that encodes a 1132 amino acid protein (127.7 kDa) (Fig. 2B). Its 45 bp 5' UTR had some sequences similar to those described in the 5 ' termini of some chrysoviruses. For instance, a GAUAAA sequence in position 12 (Ghabrial, 2010), and an AAAAAA sequence in position 4 (Jamal et al., 2010). The 3' UTR is 42 bp long. The amino acid sequence of the unique ORF present in dsRNA3 exhibited the highest identity to the RdRp of Magnaporthe oryzae chrysovirus 1 (50\% identity) (Urayama, et al., 2010), and also resembled other chrysovirus replicases. The eight conserved motifs of RdRps of dsRNA viruses (Bruenn, 1993) were present in the amino acid sequence. The sequence of dsRNA3 has been deposited in the EMBL nucleotide database with accession number FR750563.

No clones were obtained from dsRNA2, but its transmission was independent of other dsRNAs and it could constitute the complete genome of another virus that was tentatively named $\mathrm{TcV} 3$.

Phylogenetic analyses based on alignments of the amino acid sequence of the CP and RdRp of selected members of the Totiviridae and Chrysoviridae (Supplemental material Table 1) and of 
TcV1 (dsRNA1) and dsRNA3 (Fig. 3) were made. MEGA software (Kumar et al., 2004) was used to estimate genetic distances with the Poisson correction model, and to make neighbour-joining trees. As expected, TcV1 was included in a clade within the genus Victorivirus (Fam. Totiviridae). In addition, the alignment of the 3' UTR sequences of eleven members of the Victorivirus genus and TcV1 (dsRNA1), revealed a region of $18 \mathrm{bp}$ that is conserved in most members of the genus, except for Helicobasidium mompa totivirus 1-17 (HmV-17) and Coniothyrium minitans RNA virus (CmRV) (Supplemental material Fig. 2). Several victorivirus genomes, including TcV1, end with an AUGC 3' motif. This motif and a preceding stem loop, also predicted in TcV1, have an important role in the replication of Saccharomyces cerevisiae totivirus ScV-LA (Wickner, 1996). TcV1 differs from other victoriviruses in the fact that its two ORFs are in the same reading frame and do not overlap, as occurs with most members of the genus. In TcV1 the UAA stop codon of ORF1 is immediately followed by the AUG start codon of ORF2. A study performed with a mutant of the mycovirus CHV1-EP713 proved that the non existence of an overlap between ORF1 and ORF2 does not affect the translation of ORF2 (Guo et al., 2009). Therefore, TcV1 may also follow a coupled termination reinitiation mechanism of translation, which is typical of victoriviruses (Ghabrial and Nibert, 2008).

The phylogenetic analysis also confirmed that dsRNA3 is closer to the Chrysoviridae family than to the Totiviridae (Fig. 3). Since chrysoviruses have tetrapartite genomes of 2.4-3.6 kbp (Ghabrial et al., 2005), the fact that dsRNA3 encodes a putative chysovirus RdRp supports the hypothesis of dsRNAs 3, 4, 5, and 6 being the multipartite genome of a virus, and in particular, of a member of the Chrysoviridae. We have named this virus Tolypocladium cylindrosporum virus 2 (TcV2).

In conclusion, this study presents the first reported sequences for mycoviruses infecting an entomopathogenic fungus, and adds a new member to the genus Victorivirus, TcV1. Curing and transmission experiments suggested that strain 11 of $T$. cylindrosporum was infected by three different viruses: TcV1 (dsRNA1), TcV2 (dsRNAs 3, 4, 5, 6) a hypothetical member of the Chrysoviridae family, and TcV3 (dsRNA2) an unknown virus with a genome or a replicative form of approximately $4.2 \mathrm{kbp}$. In contrast to other reports of virus transmission in mixed infections, the T. cylindrosporum viruses showed different rates of transmission to conidia, and as a result viral combinations different from those of the parental strains occurred in conidial progeny. In addition, this is the first report of the successful use of ribavirin to cure fungal viruses. However, the drug was efficient curing strains of TcV1, but not against TcV2 or TcV3. Therefore, ribavirin could be useful to cure some particular fungal viruses, and to obtain isogenic virus free strains, useful to 
study the effects of viruses in their fungal hosts, something which is largely unknown, in spite of the ubiquity of viruses in the fungal kingdom.

\section{Acknowledgements}

This research was financed by project AGL2008-01159, granted by the Spanish Ministry of Education and Science.

\section{References}

Bruenn, J.A. 1993. A closely-related group of RNA-dependent RNA-polymerases from doublestranded-RNA viruses. Nucl. Acids Res. 21, 5667-5669.

Carroll, K., Wickner, R.B. 1995. Translation and M1 double stranded RNA propagation: Mak18=Rpl41b and cycloheximide curing. J. Bacteriol. 177, 2887-2891.

Chu, Y.M., Lim, W.S., Yea, S.J., Cho, J.D., Lee, Y.W., Kim, K.H. 2004. Complexity of dsRNA mycovirus isolated from Fusarium graminearum. Virus Genes. 28, 135-143.

Coutts, R.H.A., Livieratos, I.C. 2003. A rapid method for sequencing the $5^{\prime}$ and $3^{\prime}$ termini of double-stranded RNA viral templates using RLM-RACE. J. Phytopathol. 151, 525-527.

Fujimura, T., Wickner, R.B. 1988. Gene overlap results in viral protein having an RNA binding domain and a major coat protein domain. Cell. 55, 663-671.

Gams, W. 1971. Tolypocladium, eine Hyphomycetengattung mit geschwollenen Phialiden. Persoonia. 6, 185-191.

Ghabrial, S.A., Jiang, D., Caston, J.R. 2005. Chrysoviridae, in: Fauquet, C.M., Mayo, M.A., Maniloff, J., Desselberger, U., Ball, L.A. (Eds.), Virus taxonomy eighth report of the international committee on taxonomy of viruses. San Diego, pp. 591-595.

Ghabrial, S.A., Nibert, M.L. 2008. Victorivirus, a new genus of fungal viruses in the family Totiviridae. Arch. Virol. 154, 373-379.

Ghabrial, S.A., Suzuki, N. 2009. Viruses of Plant Pathogenic Fungi. Annu. Rev. Phytopathol. 47, 353-384.

Ghabrial, S.A. 2010. Totiviruses, in: Mahy, B.W.J., Van Regenmortel, M.H.V. (Eds.), Desk encyclopedia of plant and fungal virology. Elsevier, Oxford, pp 565-576.

Guo, L., Sun, L., Chiba, S., Araki, H., Suzuki, N. 2009. Coupled termination/reinitiation for translation of the downstream open reading frame B of the prototypic hypovirus CHV1EP713. Nucl. Acids Res. 37, 3645-3659. 
Herrero, N., Sánchez Márquez, S., Zabalgogeazcoa I. 2009. Mycoviruses are common among different species of endophytic fungi of grasses. Arch. Virol. 154, 327-30.

Herrero, N., Pérez Sánchez, R., Oleaga, A., Zabalgogeazcoa, I. 2011. Tick pathogenicity, thermal tolerance and virus infection in Tolypocladium cylindrosporum. Annals of Applied Biology. In press.

Ihrmark, K., Johannesson, H., Stenström, E., Stenlid J. 2002. Transmission of double-stranded RNA in Heterobasidion annosum. Fungal Genet. Biol. 36, 147-154.

Inglis, P.W., Valadares-Inglis, M.C. 1997. Rapid isolation of double-stranded RNAs from entomopathogenic species of the fungus Paecilomyces using a commercial minicolumn system. J. Virol. Methods. 67, 113-116.

Jamal, A., Bignell, E.M., Coutts, R.H.A. 2010. Complete nucleotide sequences of four dsRNAs associated with a new chrysovirus infecting Aspergillus fumigatus. Virus Res. 153, 64-70.

Jiang, D.H., Ghabrial, S.A. 2004. Molecular characterization of Penicillium chrysogenum virus: reconsideration of the taxonomy of the genus Chrysovirus. J. Gen. Virol. 85, 2111-2121.

Kang, J.G., Wu, J.C., Bruenn, J.A., Park, C.M. 2001. The H1 double-stranded RNA genome of Ustilago maydis virus-H1 encodes a polyprotein that contains structural motifs for capsid polypeptide, papain-like protease, and RNA-dependent RNA polymerase. Virus Res. 76, 183-189.

Kumar, S., Tamura, K., Nei, M. 2004. MEGA3: integrated software for molecular evolutionary genetics analysis and sequence alignment. Brief Bioinform. 5, 150-163.

Laemmli, U.K. 1970. Cleavage of structural proteins during the assembly of the head of bacteriophage T4. Nature. 227, 680-685.

Lam, T.N.C., Goettel, M.S., Soares, G.G. 1988. Host records for the entomopathogenic hyphomycete Tolypocladium cylindrosporum. Fla. Entomol. 71, 86-89.

Mahmoud, S.Y.M., Hosseny, M.H., Abdel-Ghaffar, M.H. 2009. Evaluation of some therapies to eliminate potato Y potyvirus from potato plants. Int. J. Virol. 5, 64-76.

Martins, M.K., Furlaneto, M.C., Sosa-Gomez D.R., Rodrigues Faria M., Pelegrinelli Fungaro M.H. 1999. Double-stranded RNA in the entomopathogenic fungus Metarhizium flavoviride. Curr Genet. 36, 94-97.

Melzer, M.J., Bidochka, M.J. 1998. Diversity of double-stranded RNA viruses within populations of entomopathogenic fungi and potential implications for fungal growth and virulence. Mycologia 90, 586-594.

Morris, T.J., Dodds, J.A. 1979. Isolation and analysis of double-stranded-RNA from virus-infected plant and fungal tissue. Phytopathology. 69, 854-858. 
Park, Y., Chen, X.B., Punja, Z.K. 2006. Molecular and biological characterization of a mitovirus in Chalara elegans (Thielaviopsis basicola). Phytopathology. 96, 468-479.

Parker, W.B. 2005. Metabolism and antiviral activity of ribavirin. Virus Res. 107, 165-171.

Romo, M., Leuchtmann, A., García, B., Zabalgogeazcoa, I. 2007. A totivirus infecting the mutualistic fungal endophyte Epichloë festucae. Virus Res. 124, 38-43.

Sánchez Márquez, S., Bills, G., Domínguez L., Zabalgogeazcoa I. 2010. Endophytic mycobiota of leaves and roots of the grass Holcus lanatus. Fungal Div. 41, 115-123.

Souza Azevedo, A.C., Sosa-Gomez, D.R., Rodrigues Faria, M., Pelegrinelli Fungaro, M.H. 2000. Effects of double-stranded RNA on virulence of Paecilomyces fumosoroseus (Deuteromycotina: Hyphomycetes) against the silverleaf whitefly, Bemisia tabaci strain B (Homoptera: Aleyrodidae). Genet. Mol. Biol. 23, 61-63.

Tuomivirta, T.T., Hantula, J. 2005. Three unrelated viruses occur in a single isolate of Gremmeniella abietina var. abietina type A. Virus Res. 110, 31-39.

Urayama, S., Kato, S., Suzuki, Y., Aoki, N., Le, M.T., Arie, T., Teraoka, T., Fukuhara, T., Moriyama, H. 2010. Mycoviruses related to chrysovirus affect vegetative growth in the rice blast fungus Magnaporthe oryzae. J. Gen. Virol. 91, 3085-3094.

Vega, F.E., Posada, F., Aime, M.C., Pava-Ripoll, M., Infante, F., Rehner, S.A. 2008 Entomopathogenic fungal endophytes. Biol. Control. 46, 72-82.

Wickner, R.B. 1996. Double-stranded RNA viruses of Saccharomyces cerevisiae. Microbiol. Rev. $60,250-265$.

Zabalgogeazcoa, I., Benito, E.P., García Ciudad, A., García Criado, B., Eslava, A.P. 1998. Doublestranded RNA and virus like particles in the grass endophyte Epichloë festucae. Mycol. Res. 102, 914-918. 


\section{Figures}

Fig. 1. (A) Electrophoretic banding patterns of the dsRNA elements present in strains 11 of $T$. cylindrosporum. Lane $\mathrm{M}$ contains $\lambda$-HindIII size marker; numbers on the left and right indicate kbp. (B) Enlarged picture of the larger band following extended electrophoresis.

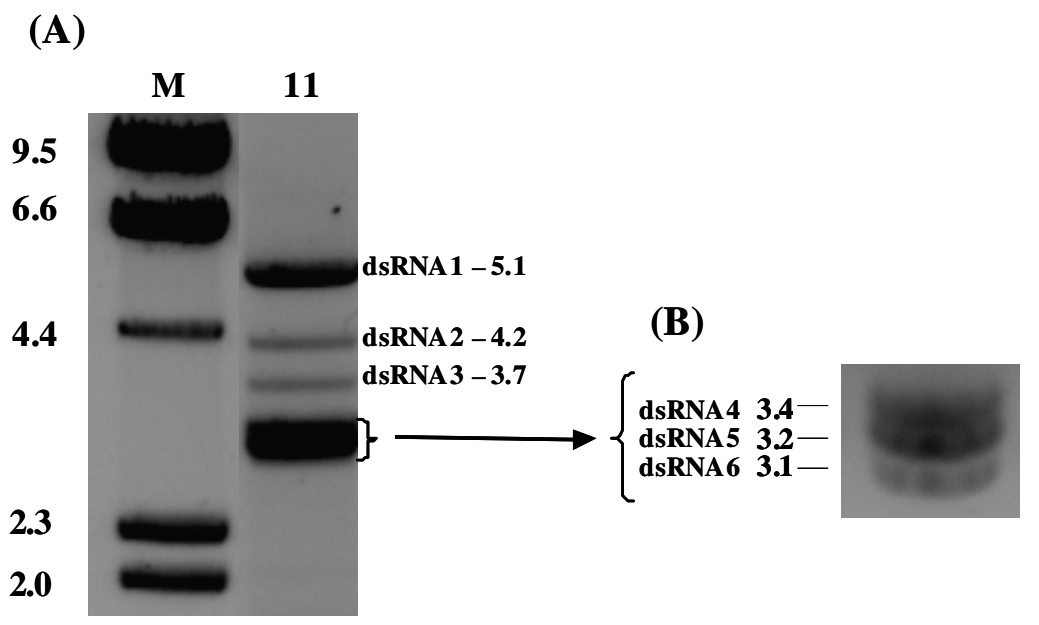


Fig. 2. (A) Genome organization of Tolypocladium cylindrosporum virus 1 (TcV1). The $5196 \mathrm{kbp}$ genome contains two ORFs; ORF1 encodes a putative CP and ORF2 a putative RdRp. (B) Organization of dsRNA 3, a 3486 bp element which encodes a putative RdRp. (C) Isometric viruslike particles observed by TEM from a purified virus preparation from T. cylindrosporum 11-1L isolate harbouring only dsRNA1. Bar $=25 \mathrm{~nm}$. (D) SDS-PAGE analysis of purified TcV1 particles. Lane M, molecular weight marker (kDa on left); lane 1, SDS-treated TcV1 virions. The structural proteins were visualized by coomassie blue staining. The $79.7 \mathrm{kDa}$ protein purified by electrophoresis $(\mathrm{CP})$ has a molecular weight similar to the one estimated for the hypothetical protein coded by ORF1 (79.87 kDa).

(A)

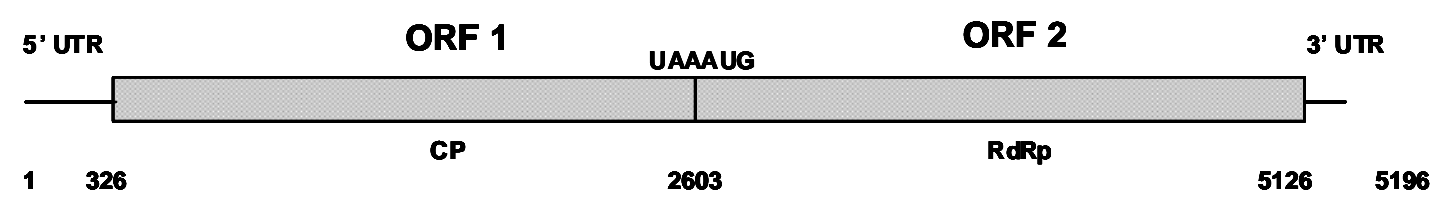

(B)

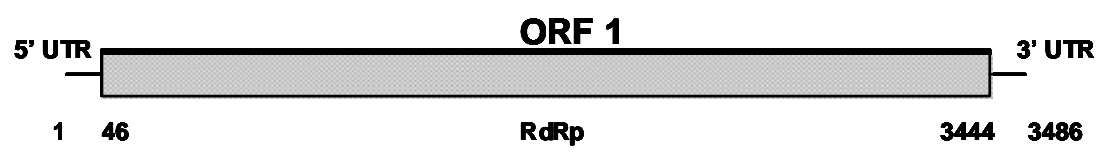

(C)

(D)
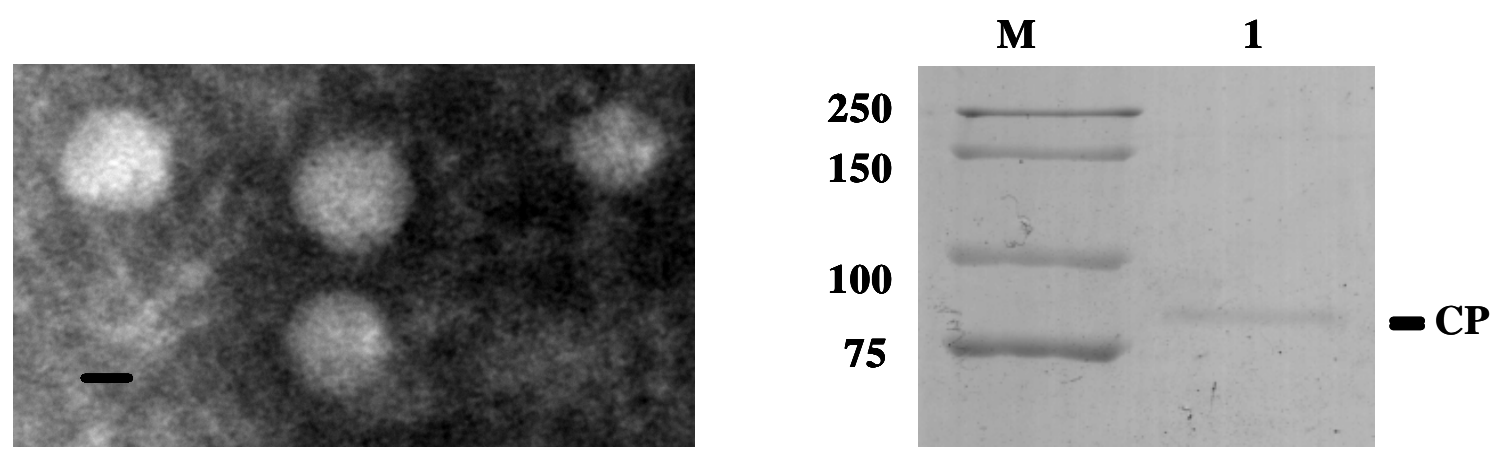
Fig. 3. (A) Phylogenetic tree of viruses of the family Totiviridae based on $\mathrm{CP}$ amino acid sequences. (B) Phylogenetic tree based on RdRp amino acid sequences of members of the Totiviridae and Chrysoviridae families. The unrooted trees were based on the neighbour-joining method. Numbers at nodes represent bootstrap values as percentages estimated by 1000 replicates. The accession numbers of sequences used in the analyses are given in the supplemental material.

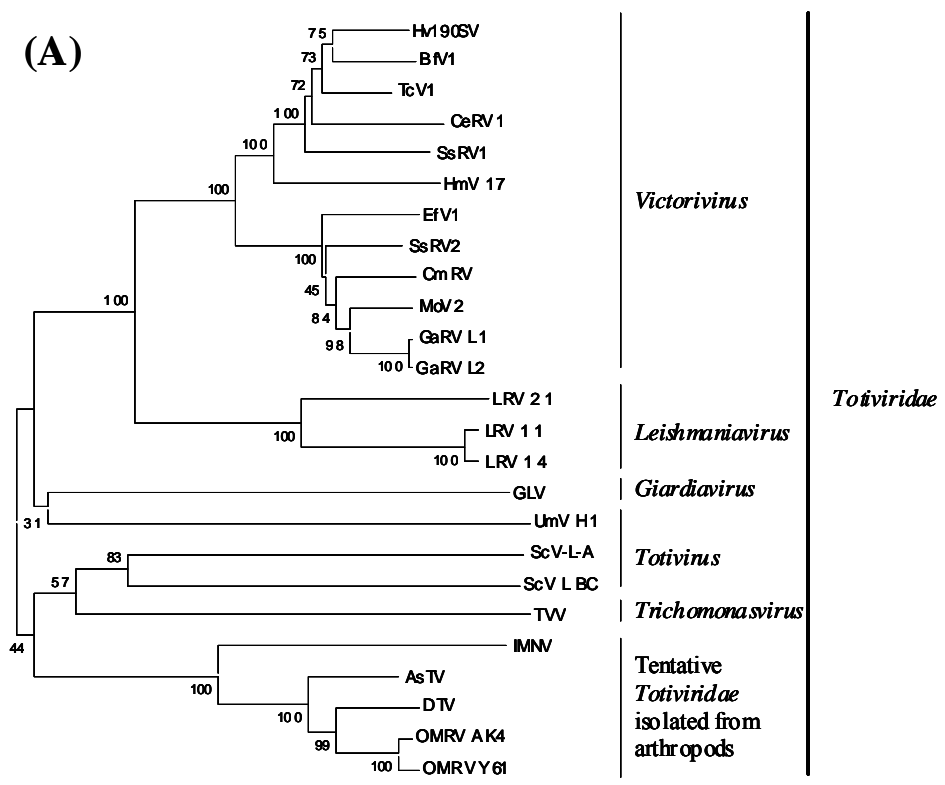

(B)

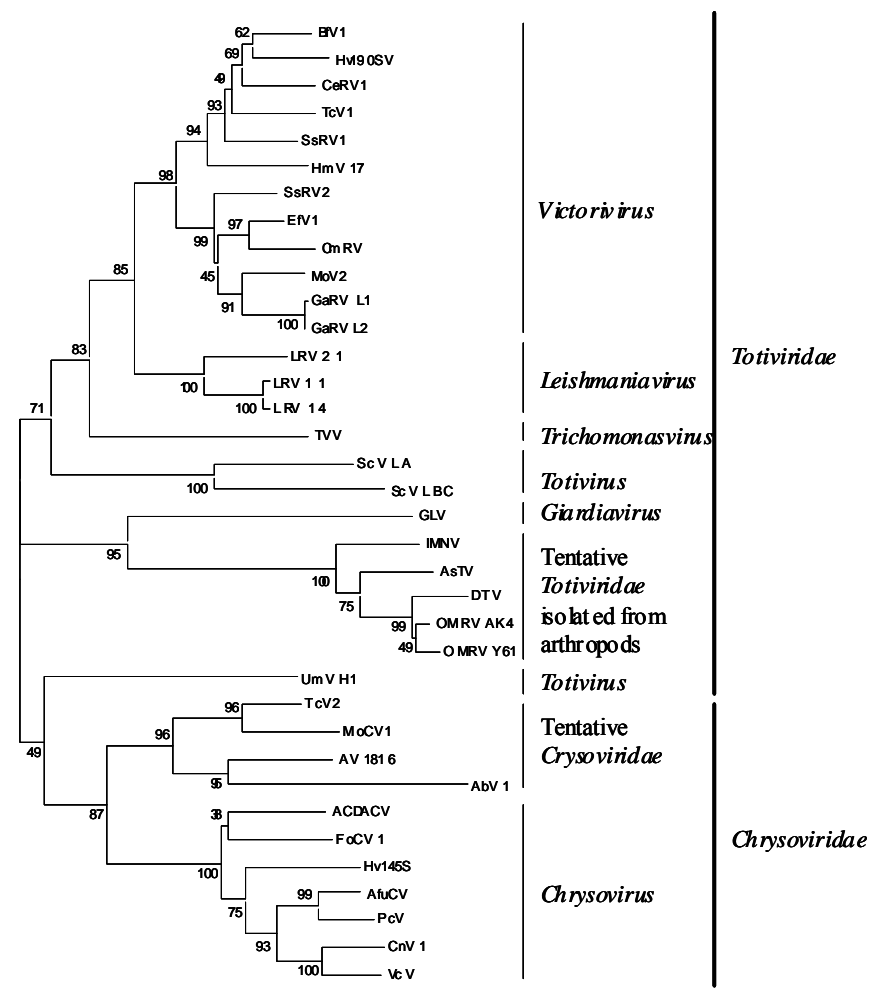




\section{Supplemental material}

Supplemental Table 1. Members of the families Chrysoviridae and Totiviridae used for phylogenetic analysis. Species used in the alignment for the design of the Totioligo primer are in bold type.

\begin{tabular}{|c|c|c|}
\hline Virus & Abbreviation & $\begin{array}{c}\text { EMBL } \\
\text { accession no. }\end{array}$ \\
\hline Amasya cherry disease associated chrysovirus & ACDACV & AJ781397 \\
\hline Agaricus bisporus virus 1 & $\mathrm{AbV} 1$ & CAA64144 \\
\hline Armigeres subalbatus totivirus & AsTV & EU715328 \\
\hline Aspergillus fumigatus chrysovirus & AfuCV & FN178512 \\
\hline Aspergillus mycovirus 1816 & AV-1816 & EU289896 \\
\hline Botryotinia fuckeliana totivirus 1 & BfV1 & CAM33265.1 \\
\hline Chalara elegans RNA virus 1 & CeRV1 & AY561500 \\
\hline Coniothyrium minitans RNA virus & $\mathrm{CmRV}$ & AAO14999.1 \\
\hline Cryphonectria nitschkei chrysovirus 1 & $\mathrm{CnV}-1$ & ACT79255 \\
\hline Drosophila melanogaster totivirus & DTV & GQ342961 \\
\hline Epichloë festucae vírus 1 & EfV1 & CAK02788.1 \\
\hline Fusarium oxysporum chrysovirus 1 & FoCV-1 & EF152346 \\
\hline Giardia lamblia virus & GLV & L13218 \\
\hline Gremmeniella abietina RNA virus L1 & GaRV-L1 & AF337175 \\
\hline Gremmeniella abietina RNA virus-L2 & GaRV-L2 & AY615210 \\
\hline Helicobasidium mompa totivirus 1-17 & $\mathrm{HmV}-17$ & BAC 81754.1 \\
\hline Helminthosporium victoriae-145S virus & Hv-145S & AF297176 \\
\hline Helminthosporium victoriae virus $190 \mathrm{~S}$ & Hv-190SV & AAB94791.2 \\
\hline Infectious myonecrosis virus & IMNV & EF061744 \\
\hline Leishmania RNA virus 1-1 & LRV1-1 & M92355 \\
\hline Leishmania RNA virus $2-1$ & LRV2-1 & U32108 \\
\hline Leishmania RNA virus 1-4 & LRV1-4 & U01899 \\
\hline Magnaporthe oryzae virus 2 & MoV 2 & BAF98178.1 \\
\hline Magnaporthe oryzae chrysovirus 1 & MoCV1 & BAJ15133 \\
\hline Omono River virus-AK4 & OMRV-AK4 & AB555544 \\
\hline Omono River virus-Y61 & OMRV-Y61 & AB555545 \\
\hline Penicillium chrysogenum virus & $\mathrm{PcV}$ & AF296439 \\
\hline Saccharomyces cerevisiae virus-LA & ScV-L-A & J04692 \\
\hline Saccharomyces cerevisiae virus-L-BC & ScV-L-BC & U01060 \\
\hline Sphaeropsis sapinea RNA vírus 1 & SsRV-1 & AAD11601.1 \\
\hline Sphaeropsis sapinea RNA vírus 2 & SsRV-2 & AAD11603.1 \\
\hline Tolypocladium cylindrosporum virus 1 & $\mathrm{TcV} 1$ & FR750562 \\
\hline Tolypocladium cylindrosporum virus 2 & TcV 2 & FR750563 \\
\hline Trichomonas vaginalis virus 2 & TVV & AF127178 \\
\hline Ustilago maydis virus $\mathrm{H} 1$ & UmV-H1 & U01059 \\
\hline Verticillium chrysogenum virus & $\mathrm{VcV}$ & ADG21213 \\
\hline
\end{tabular}


Supplemental Fig. 2. Alignment of the 3' UTR sequences of eleven members of the Victorivirus genus and TcV1. A conserved sequence (blue letters) among members of this genus is indicated.

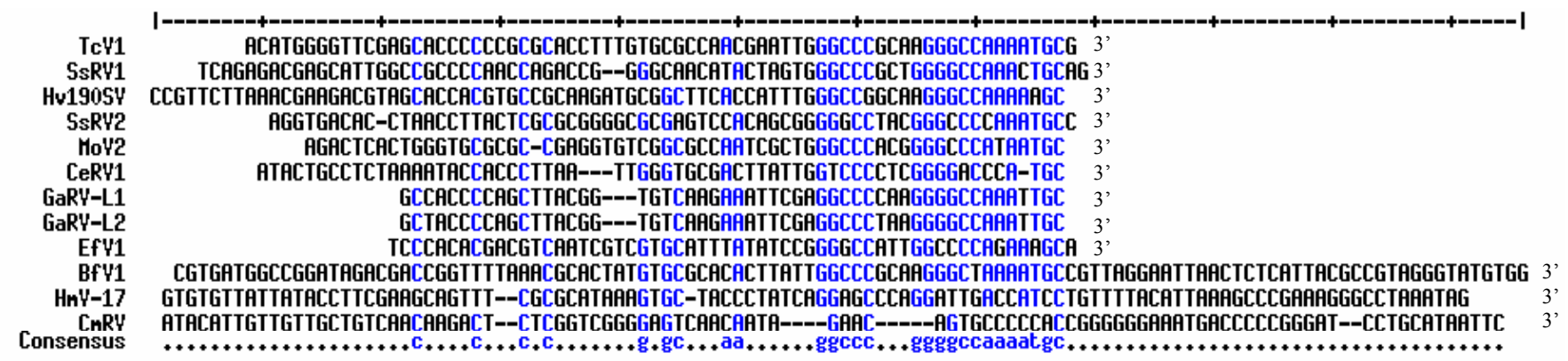

Supplemental Fig. 1. Three contigs were obtained from assembling 35 cDNA clones obtained using dsRNA from strain 11 as template. (A) Northern blot hibridization using as a probe a clone belonging to the contig 1. (B). Northern hybridation using as probes clones from contigs 2 (B1) and contig 3 (B2). The hybridizations show that contig 1 belongs to dsRNA 3 while contigs 2 and 3 are part of dsRNA 1.

(A)

(B)

(B1)

(B2)

M 11

8.0

6.0

5.0

4.0

3.0

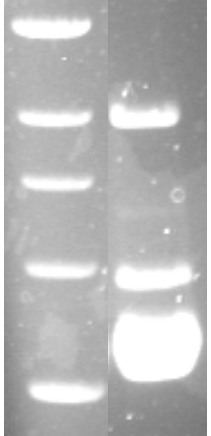

M 11

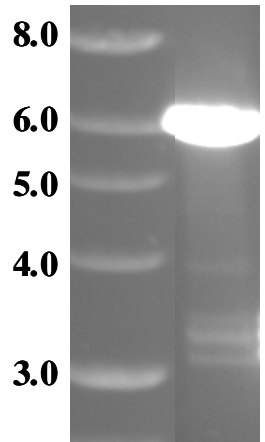

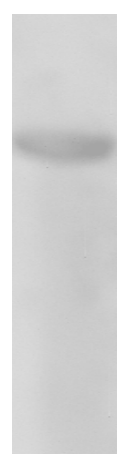

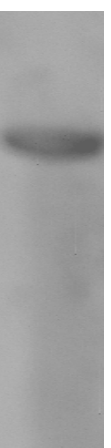

